\title{
Label-free microfluidic chip for the identification of mesothelial cell clusters in pleural effusion
}

\author{
LILI ZHAO $^{1 *}$, MENG ZHAO $^{2 *}$, YU YANG $^{1}$, YAJUN GU $^{1}$, FANG ZHENG $^{1}$, \\ XUAN WANG ${ }^{3}$, ZHIYUAN ZHENG ${ }^{4}$ and XUGUO SUN ${ }^{1}$ \\ ${ }^{1}$ Department of Laboratory Science, School of Laboratory Medicine, Tianjin Medical University, Tianjin 300203; \\ ${ }^{2}$ Key Laboratory of Computer Vision and System of Ministry of Education, School of Computer Science and Engineering, \\ Tianjin University of Technology, Tianjin 300384; ${ }^{3}$ Department of Clinical Laboratory, Tianjin Chest Hospital, \\ Tianjin 300051; ${ }^{4}$ Department of Bone Science, North China University of Science and Technology Affiliated Hospital, \\ Tangshan, Hebei 063000, P.R. China
}

Received February 2, 2018; Accepted January 28, 2019

DOI: $10.3892 / \mathrm{ol} .2019 .10118$

\begin{abstract}
The detection of tumor cells and clusters in pleural effusion assists in the diagnosis of lung cancer. The proportion of tumor cells and clusters to the total number of cells in each patient varies substantially due to individual differences and the severity of the disease. The identification of one tumor cell or cluster from a large number of pleural effusions is the main challenge for hydrothorax tumor cell detection techniques. In the present study, by using A549 lung cancer and Met-5A mesothelial cell lines, a label-free microfluidic chip based on cell cluster size was designed. By setting the parameters of the chip, individual cells and clusters were able to enter different microfluidic channels. Subsequent to non-specific staining, the recovered components were stained using acridine orange (AO). A charge-coupled device camera was used to captured images of the cell, and the features of these cells were analyzed in their R and G channels using Matlab software to establish the characteristics and finally differentiate between the tumor and non-tumor cell or clusters. According to the results, when inlet $A$ and $B$ were under a velocity of 10 and $8.5 \mathrm{ml} / \mathrm{h}$, respectively, the tumor cell clusters were successfully collected through microfluidic channels III-V, with a recovery rate of $\sim 80 \%$. Subsequent to staining with $\mathrm{AO}$, the feature values in the $\mathrm{R}$ and $\mathrm{G}$ channels were identified, and initial differentiation
\end{abstract}

Correspondence to: Professor Xuguo Sun, Department of Laboratory Science, School of Laboratory Medicine, Tianjin Medical University, 1 Guangdong Road, Hexi, Tianjin 300203, P.R. China

E-mail: sunxuguo@tmu.edu.cn

${ }^{*}$ Contributed equally

Abbreviations: AO, acridine orange; DMEM, Dulbecco's modified Eagle's medium; PBS, phosphate buffer solution

Key words: pleural effusion, cell cluster, mesothelial cell, lung cancer, microfluidic chip, acridine orange, image processing was achieved. The present study combined the microfluidic chip, which is based on cluster size, with a computer identification method for pleural effusion. The successful differentiation of tumor cell clusters from non-tumor clusters provides the basis for the identification of tumor clusters in hydrothorax.

\section{Introduction}

The incidence of lung cancer has risen in patients in developed countries, with an estimated 1,800,000 new cases of lung cancer diagnosed in 2012 (1). In cases of primary lung cancer (2-4) and in the lung metastases of patients with other types of cancer $(5,6)$, tumor cells and clusters may occasionally be identified in pleural effusion. As a result, the detection of cancer cells in pleural effusion samples, which are considered to be liquid biopsy specimens, may assist in the diagnosis of lung cancer $(2,7)$. Rather than clusters, previous investigations (8) have focused on single tumor cells, and as a result there has been a lack of systematic research on tumor clusters in pleural effusion, and whether there is any notable association between tumor clusters in pleural effusion and the diagnosis or metastases of lung cancer. The current lack of effective separation and detection techniques for hydrothorax tumor clusters may be one of the factors contributing to the limited investigation in this area.

Erythrocytes, granulocytes, lymphocytes, alveolar macrophages, mesothelial cells and tumor cells can be observed in pleural effusions (9). The classification of these cells is based on their morphological features. Clinical cytopathologists identify tumor cells in pleural effusions by their morphological character, thereby identifying the difference between tumor and non-tumor cells (9). For situations when cells are under inflammatory stimulation or metaplasia, the morphology becomes indecipherable, particularly for mesothelial cells or clusters $(8,10)$. Therefore, immunolabeling techniques are able to assist with tumor cell identification $(11,12)$.

Numerous studies have revealed that the biomarkers of granulocytes, lymphocytes and epithelial cells may improve the analysis of pleural effusion through the use of flow cytometry, which can assist with clinical diagnosis and 
evaluation of the clinical therapeutic effect $(13,14)$. However, using this method makes it difficult to evaluate the biological properties of tumor clusters. In terms of the immune affinity technique, antibodies may be used for the screening of tumor cells in the hydrothorax, which can assist in diagnosing lung cancer $(15,16)$, however, this type of technology is circumscribed to the analysis of tumor clusters in the hydrothorax.

Clinically, the quantity of the collected pleural effusion required is $>20 \mathrm{ml}$ (17), however, an increasing number of reports have identified that a larger volume of specimen may improve cytological sensitivity in pleural effusions $(18,19)$. At present, the process of the pathological diagnosis of pleural effusion cells, whether by a direct smear or through centrifugation enrichment followed by observation under a microscope, uses only part of the sample for assessment, leading to the loss of tumor cells or clusters, which require detection (8).

Numerous studies have reported that image recognition can be used for cell type classification (20-22). Additionally, a method based on the cell image feature classification model has been established, and can successfully identify tumor and non-tumor cells (23), thereby providing the foundation for future investigations to discern tumor clusters in pleural effusion.

In order to avoid abnormally enlarged epithelial cells and non-tumor cell clusters or fibrous protein aggregations coiling around parts of the cell constituents, which may influence test results, a size-based microfluidic chip was designed in the present study, in order to separate the clusters. By recruiting the clusters and performing non-specific labeling of the nucleotides with acridine orange (AO) fluorescence, based on the results of previous studies $(24,25)$, combined with the propagation of morphological differences between the tumor and non-tumor cells or clusters, the present study was able to identify tumor cells or clusters, and identify hydrothorax tumor cell clusters in one step.

\section{Materials and methods}

Sample preparation. In the present study, two cell lines were recruited. One of the cell lines used was a lung cancer cell line (A549) obtained from the Institute of Lung Cancer, General Hospital of Tianjin Medical University (Tianjin, China). The other cell line used was an immortalized mesothelial cell line (Met-5A; cat. no. BNCC341331; BeNa Culture Collection, Jiangsu, China), which had been transfected with the pRSV-T plasmid (an SV40 ori-construct containing the SV40 early region and the Rous sarcoma virus long terminal repeat) and cloned. The cells were cultured under $37^{\circ} \mathrm{C}$ and $5 \% \mathrm{CO}_{2}$ separately in Dulbecco's modified eagle's medium (DMEM) basic and DMEM-high glucose culture medium (Beijing Solarbio Science \& Technology Co., Ltd., Beijing, China) with $10 \%$ fetal bovine serum (FBS; Biological Industries, Kibbutz Beit Haemek, Israel) and $1 \%$ Penicillin-Streptomycin (Beijing Solarbio Science \& Technology Co., Ltd., Beijing, China) in a $25 \mathrm{~cm}^{2}$ rectangular canted neck cell culture flask with a vent cap. When cell growth reached $\sim 80 \%$ of the area of the culture flask, $600 \mu 1$ of $0.25 \%$ Trypsin-EDTA solution (Beijing Solarbio Science \& Technology Co., Ltd.) was used to digest the cells, followed by centrifugation at $1,721 \mathrm{x} \mathrm{g}$ for $10 \mathrm{~min}$ at $25^{\circ} \mathrm{C}$. Subsequently, $3 \mathrm{ml}$ phosphate buffer solution (PBS; pH 7.4) was added, followed by careful blowing 3-5 times to resuspend the cells and establish clusters using a disposable pipette. A total of $10 \mu 1$ of the sample was selected to manually count the number of cells on a Neubauer hemocytometer under a light microscope (x400 magnification), followed by adjustment of the concentration of the sample to $1 \times 10^{8}-1 \times 10^{10} \mathrm{cell} / \mathrm{ml}$ (with one cluster treated as one cell) and then the sample was set aside.

The white blood cells (WBCs) were harvested from a healthy male donor's (age, 25 years) whole blood obtained at the Affiliated Hospital of Chinese Medicine Research Institute (Tianjin, China) in January 2017. A total of $500 \mu 1$ blood was collected, and $1.5 \mathrm{ml}$ red blood cell lysis buffer (Beijing Solarbio Science \& Technology Co., Ltd.) was added. The sample was then gently swirled 10 times and then placed on ice $\left(4^{\circ} \mathrm{C}\right)$ for $15 \mathrm{~min}$. At a temperature of $4^{\circ} \mathrm{C}$, the sample was centrifuged at $191 \mathrm{x}$ g for $10 \mathrm{~min}$ and the supernatant was discarded, followed by the addition of $1 \mathrm{ml}$ red blood cell lysis buffer, which was then placed on ice $\left(4^{\circ} \mathrm{C}\right)$ for $15 \mathrm{~min}$. The sample was then centrifuged at $1,721 \mathrm{x}$ g for $10 \mathrm{~min}$ at $4^{\circ} \mathrm{C}$, following which the supernatant was discarded, and $500 \mu \mathrm{l}$ PBS (pH 7.4) was added. A disposable pipette was used to suspend the cells 3-5 times, and the sample was set aside.

Chip characteristics. Prior to the experiment, the chip was rinsed using PBS (pH 7.4). Inlet A (samples) and B (buffer) were connected with syringe pump (cat no. RSP01-BD, Jiashan Ristron, Electronic Technology Co., Ltd., Jiashan, China) No. 1 and No. 2. Subsequent to operating at an experimental programmed flow rate (e.g. $\mathrm{Va}=10 \mathrm{ml} / \mathrm{h}, \mathrm{Vb}=8.5 \mathrm{ml} / \mathrm{h}$ where $\mathrm{Va}$ represents to velocity of inlet $\mathrm{A}$ and $\mathrm{Vb}$ represents the velocity of inlet $B$ ), the chip was washed using PBS buffer from inlet B at a velocity of $100 \mathrm{ml} / \mathrm{h}$ for $30 \mathrm{sec}$ to wash out the residual components within the channels, and the sample in the five outlets was finally collected.

In the cell velocity-filling experiment, the sample was loaded with whole blood diluted with PBS (1:10 dilution) at a final volume of $3 \mathrm{ml}$. The ratio and speed of the entrance velocity were then set, the chip was run for $5 \mathrm{~min}$, and the filling rate of cells in each channel was observed and recorded under a light microscope (x40 magnification).

In the recovery experiment, the prepared A549 cell suspension and PBS buffer were assembled into syringe pumps A and B, respectively. A series of inlet velocities were set and run for $10 \mathrm{~min}$, following which the cells were collected from all outlets. The different cluster groups $(2,3,4,5-6,7-10,11-15$ and $>16$ cells/cluster) were counted manually, and the proportion of each cluster type from each outlet was calculated. The total recovery rate was determined by adding the number of clusters collected from all channels, and the distribution rate of each cluster in each channel group under different velocity pairs was calculated. All trials were repeated five times.

Trypan blue (Beijing Solarbio Science \& Technology Co., Ltd.) was used for the viability experiment. The sample was prepared with an A549 cell cluster using the aforementioned method in PBS (pH 7.4) solution. Prior to the chip preparation process, a $10 \mu 1$ sample was selected for trypan blue staining. By evenly mixing the sample and the $0.4 \%$ trypan blue reagent at a ratio of $9: 1$, a final concentration of $0.04 \%$ was prepared. Following staining at $25^{\circ} \mathrm{C}$ for $3 \mathrm{~min}$, at least 200 cells were counted manually under a light microscope 
(x100 magnification) in $3 \mathrm{~min}$, in order to obtain the control group activity. Subsequent to running the chip sorting process for $10 \mathrm{~min}$, the samples were recovered from each outlet, the staining process was repeated and the viability of the experimental group was obtained. For all groups, the experiment was repeated three times.

Fluid stimulation. Subsequent to the construction of a whole chip model with a commercial software package (Solid Works, Version 2014, Dassault Systemes S.A, Vélizy-Villacoublay, France), fluid stimulation was performed using ANSYS Fluent (version 16.0, ANSYS, Inc., Canonsburg, PA, USA). The simulating medium used was water. By simulating a series of velocity conditions, the shear stress results in each region of the chip were obtained.

Cell staining and parameter settings. The clusters of each cell line recovered from the chip were stained with AO. The AO fluorescent dye $(60 \mu \mathrm{mol} / \mathrm{l}$; AAT Bioquest, Inc., Sunnyvale, CA, USA) was mixed with the sample at a proportion of $1: 5$, with a final concentration of $10 \mu \mathrm{mol} / 1$. Staining was performed for $10-15 \mathrm{~min}$ at $25^{\circ} \mathrm{C}$. A total of $10 \mu \mathrm{l}$ sample was placed onto a glass slide and images were captured under $\mathrm{x} 40$ magnification with a fluorescence microscope (Eclipse Ni; Nikon Corporation, Tokyo, Japan) with a charge-coupled device camera (DS-Ril; Nikon Corporation) and saved using NIS-Elements F (ver 4.30.01, Nikon Corporation) software. The exposure time was $80-100 \mathrm{~ms}$ and the optical gain was $\mathrm{x} 4.0$.

Cell modeling. The operating platform used for the cell modeling was Matlab (ver 2014a, MathWorks, Inc., Natick, MA, USA). The sample was divided into cluster groups and individual cell groups, and the background in the images was processed using Microsoft Paint (ver 1709, Microsoft Corporation, Redmond, WA, USA) to ensure that each image was analyzed using a single observation objective. In total, nine types of commonly used imaging features were selected to analyze the objective component. These were as follows: i) Mean energy value, ii) energy variance, iii) mean entropy value, iv) entropy variance, v) mean contrast value, vi) contrast variance, vii) mean correlation value, viii) correlation variance and ix) color histogram. For each observation feature, eigenvalues of the Red and Green channel were analyzed, and the ratio of these two channels was calculated.

Patient pleural effusion sorting and identification experiment. Two clinical pleural effusion samples were obtained from two male patients (mean age: 61.5 years, age range: $54-69$ years), who were diagnosed with lung cancer combined with pleural effusion symptoms, from Tianjin Chest Hospital (Tianjin, China) in March 2017. From each patient, pleural effusion samples were collected and extracted into syringe 1, and PBS buffer was added to syringe 2 as the control. The chip sorting procedure was performed under the conditions of $\mathrm{Va}=10 \mathrm{ml} / \mathrm{h}$ and $\mathrm{Vb}=8.5 \mathrm{ml} / \mathrm{h}$. When the cells were recovered from each outlet of the chip, they were stained and analyzed using $\mathrm{AO}$ as described above.

Hematoxylin and eosin $(H \& E)$ staining. The lung tissues were immersed in $4 \%$ paraformaldehyde for $4 \mathrm{~h}$, and transferred to $70 \%$ ethanol. Individual lobes of the lung tissue biopsy specimens were placed in processing cassettes, dehydrated through a serial alcohol gradient, and embedded in paraffin wax blocks. Prior to immunostaining, 4- $\mu$ m-thick lung tissue sections were dewaxed in xylene, rehydrated through decreasing concentrations of ethanol and washed in PBS, followed by staining with H\&E. Following staining, the sections were dehydrated through increasing concentrations of ethanol and xylene. A fluorescence microscope (Eclipse Ni; Nikon Corporation, Tokyo, Japan; magnification x10 and x40) was used to visualize staining, a charge-coupled device camera (DS-Ril; Nikon Corporation) was used to capture images and images were saved using NIS-Elements F (version 4.30.01, Nikon Corporation) software.

Immunohistochemistry for carcinoembryonic antigen (CEA), mesothelial cells, P53 and thyroid transcription factor (TTF-1). The dewaxed 4- $\mu \mathrm{m}$-thick lung tissues were fixed in $10 \%$ neutral formalin liquid (cat. no G2161, Beijing Solarbio Science \& Technology Co., Ltd.) at $37^{\circ} \mathrm{C}$ for $30 \mathrm{~min}$ and blocked in 5\% BSA (cat. no. SW3015, Beijing Solarbio Science \& Technology Co., Ltd.) at $37^{\circ} \mathrm{C}$ for $30 \mathrm{~min}$. Primary antibodies (CEA: cat. no. MAB-0043; Mesothelial cell: cat. no. MAB-0130; P53: cat. no. MAB-0674; and TTF-1: cat. no. MAB-0677) were obtained from Fuzhou Maixin Biotechnology Development Co., Ltd. (Fuzhou, China). Following dilution to 1:100-200, the antibodies were incubated with tissues at $4^{\circ} \mathrm{C}$ overnight. The secondary antibodies [horseradish peroxidase (HRP)-conjugated goat anti-mouse IgG H\&L: cat. no. ab205719; and HRP-conjugated goat anti-rabbit IgG H\&L: cat. nos. ab205718] were from Abcam (Cambridge, UK), Following dilution to 1:500, they were incubated with tissues for $1.5 \mathrm{~h}$ at $37^{\circ} \mathrm{C}$. Subsequently, a DAB kit (cat. no. ab64238, Abcam) was used to stain the tissue.

Statistical analysis. GraphPad Prism software (version 7.0; GraphPad Software, Inc., La Jolla, CA, USA) was utilized to analyze the data in the present study. Data are presented as the mean \pm standard error of the mean. Statistical differences in the feature analysis between each group in patients were detected using an unpaired t-test, and all other analyses were performed using one-way analysis of variance. $\mathrm{P}<0.05$ was considered to indicate a statistically significant difference.

\section{Results}

Design of the identifier system. The identifier system consists of two components, the cell cluster sorting chip and image recognition.

For the first component, a microfluidic platform was constructed, controlled by a two-way injection pump, as presented in Fig. 1A. This platform consists of two injection pumps, a controller, a microfluidic chip and a fluorescence microscope. By adjusting the ratio of the sample and buffer in the chip at the inlet, the target cell cluster can be collected and analyzed from the desired outlet.

The chip contains two sample inlets (Fig. 1B), five groups of sets of different width channels and corresponding outlets. At the entrance, a set of fences was designed to equalize the distribution of the buffer. The width of the fence aperture was $10 \mu \mathrm{m}$. By taking into consideration the diversity of cell and 
A

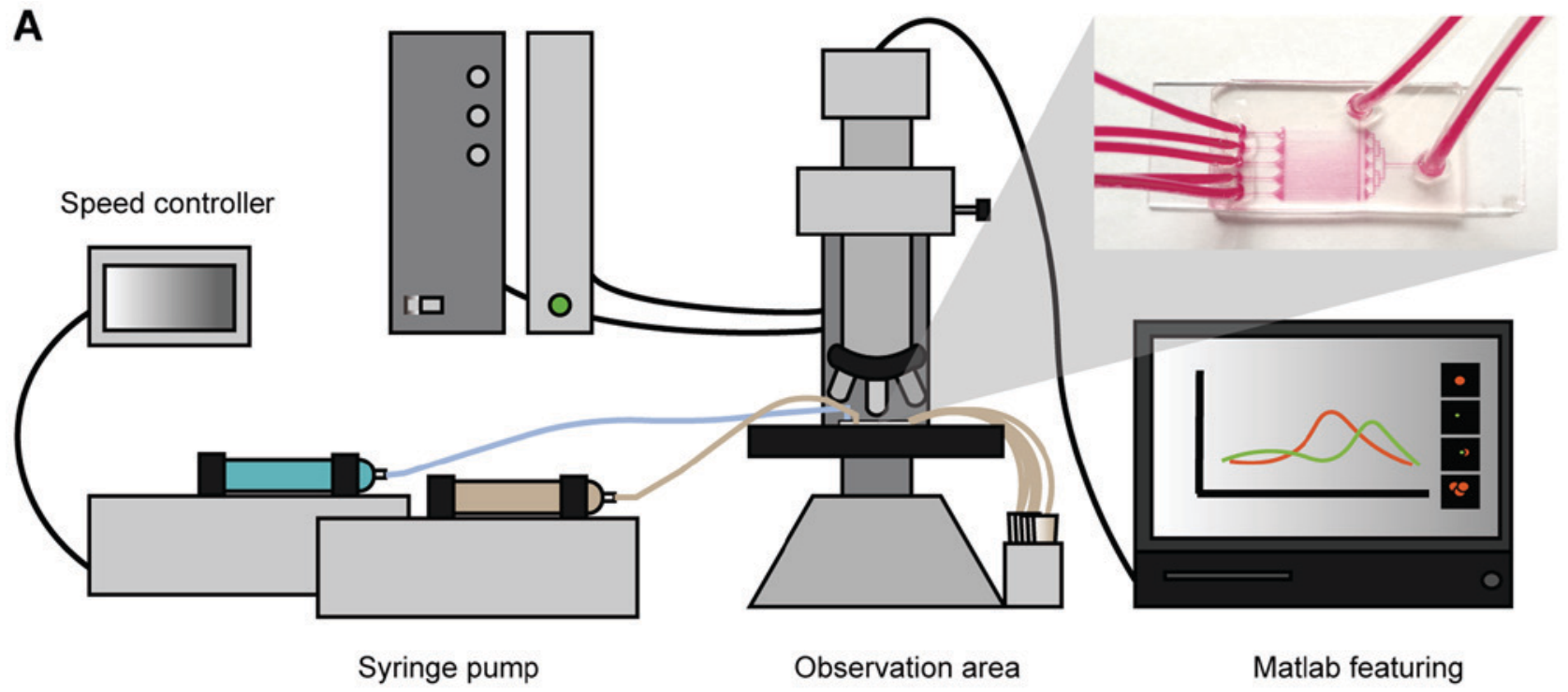

B

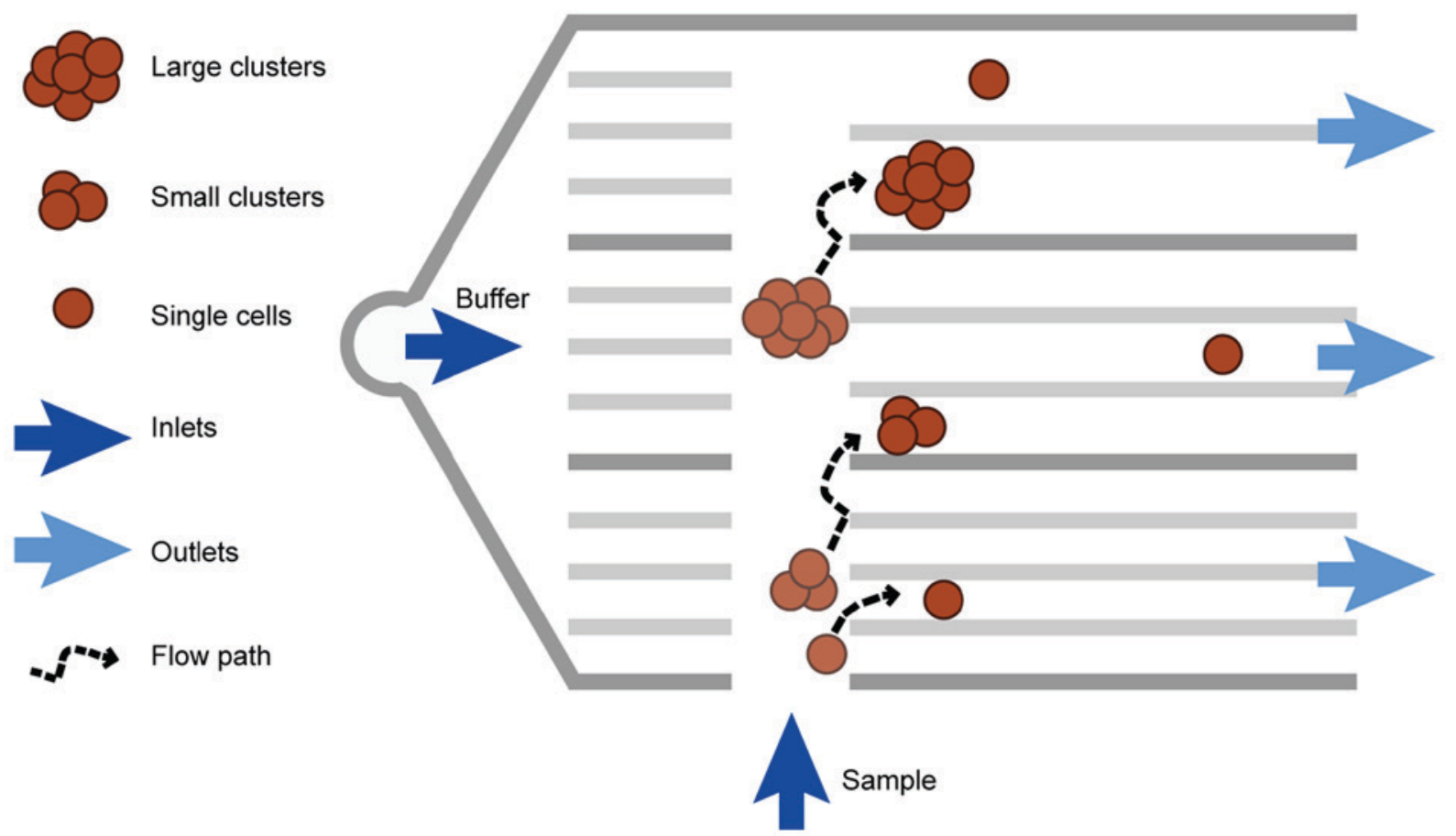

Figure 1. Schematic diagram of the identifier system created. (A) Composition of the whole system. The system includes a syringe pump-based control module, a microfluidic chip-based sorting module, a microscope-based observation module and a Matlab-based analysis module. Top right: An image of the sorting chip. (B) Schematic details of the sorting chip, which comprises two inlets, an array of fences and a series of channel groups of different sizes.

cluster sizes, the sizes of each channel group are set based on the different diameter of the target cell or cluster. The width of the five groups of channels is $10,12,15,20$ and $40 \mu \mathrm{m}$, respectively. The number of channels in the channel I-V groups ranged between 49 and 10, and the aim was to make the path long enough for the objective targets to reach the channel of best fit. The height of the channel was $50 \mu \mathrm{m}$, ensuring it is suitable for the majority of cell clusters to pass through.

As presented in Fig. 1B, when a small cell passes through a small width channel, the cell may be affected by the buffer and enter into a narrow channel. Additionally, the larger clusters that flow through may be 'flicked' by the counter force, rolling through the width of any channel.
For the second component of the identifier system, image recognition was performed using Matlab, and the target object was subsequently selected by the chip. The image recognition program was supported by analyzing the features of the AO staining.

Fluid analysis. In order to identify the optimal operating parameters of the device, which may assist in realizing the collection of single cells and different size cell clusters in the most fitting width channel group, a velocity-filling experiment was performed. The filling rate was defined as the ratio of the number of channels in which the target cells were filled in one channel group. For example, if there were 10 channels in a 

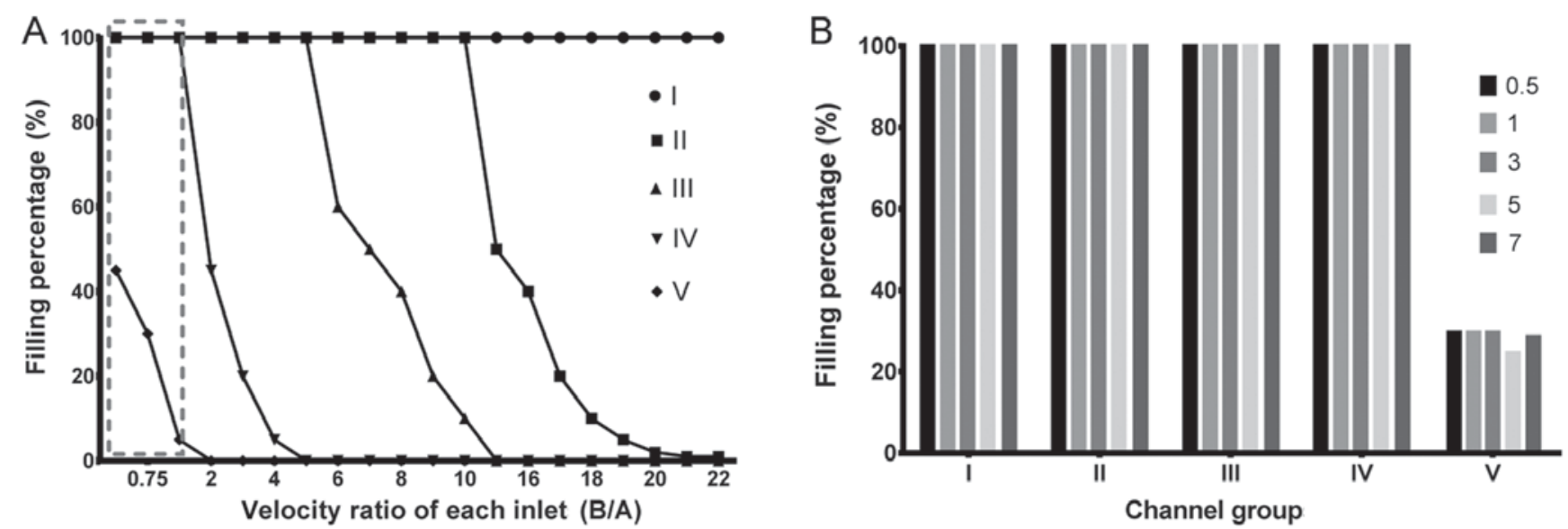

Figure 2. Cell distribution and velocity rate result. (A) Filling percentages of each channel group under differing velocity ratios. I-V represent the five channel groups. The vertical axis represents the filling percentage (\%) and the horizontal axis is the velocity ratio of each inlet (A/B). (B) Filling percentages of each channel group under different speeds $(\mathrm{ml} / \mathrm{h})$ under a stable velocity ratio of 1.00:0.85. The vertical axis represents the filling percentage $(\%)$ and the horizontal axis represents the five channel groups (I-V).

channel group, and seven channels containing cell components, then the filling rate of the channel group would be $70 \%$. In the present study, due to the minimum width of the channel being $10 \mu \mathrm{m}$, the experiment was performed using diluted whole blood in order to avoid the phenomenon of backflow plugging in the test.

Firstly, in order to move the cells close to the channel and to maintain a pressure $<20 \mathrm{~Pa}$, the inlet velocity ratio of the sample and buffer was adjusted, in order to perform the proportion-filling experiment. As presented in Fig. 2A, when the ratio of $\mathrm{Vb}: \mathrm{Va}$ was $1: 2$, channel group $\mathrm{V}$ was full of cells, resulting in no sorting effect. When the ratio reached $2: 1$, the cells in channel $\mathrm{V}$ disappeared, however the fence in channel I had produced a reverse flow (data not shown). By setting a series of ratios, the optimal ratio which satisfied channel group $\mathrm{V}$ with a certain filling rate and maintained the pressure of the intersection was identified as $\mathrm{Vb}$ : $\mathrm{Va}=1.00: 0.85$.

Secondly, in order to identify whether improvement of the flow velocity under the aforementioned ratio affects the filling rate and fluid pressure of the channel groups, a speed-filling experiment was performed. The results, as presented in Fig. 2B indicated that there was no notable change in the filling rate under these conditions, and only a relative improvement in speed was observed. According to the results of shear stress stimulation (data not shown), when $\mathrm{Va}=10 \mathrm{ml} / \mathrm{h}(\mathrm{Vb}=8.5 \mathrm{ml} / \mathrm{h}$ ), the stress value was $\sim 9.6 \mathrm{~Pa}$ at the region of inlet $\mathrm{A}$ and channel intersection, which is within the normal human arterial pressure range (5-20 Pa), indicating that it does not contribute to the mechanical separation of clusters at the intersection.

Recovery characteristics. In order to identify the maximum cell recovery rate, the recovery characteristics of each channel of the chip were analyzed at different velocity conditions. In the present study, a prepared A549 cell cluster was used, and the sample was adjusted to a concentration of $1 \times 10^{8}-1 \times 10^{10} \mathrm{cell} / \mathrm{ml}$ prior to the experiment. The numbers of all cell clusters were counted when $\mathrm{Va}=3,5,7,10$ and $12 \mathrm{ml} / \mathrm{h}$ (whilst maintaining $\mathrm{Va} / \mathrm{Vb}=0.85$ ) followed by execution of the chip-sorting process. The results, as shown in Fig. 3A, indicated that the recovery rate of a cell cluster reached its maximum value $(\sim 80 \%)$ when
$\mathrm{Va}=10 \mathrm{ml} / \mathrm{h}$. As shown in Fig. 3B, the distribution results of the cell cluster indicated that channel IV harvested the majority of the clusters under all flow rates.

In order to identify the distribution situation of various cluster groups $(2,3,4,5-6,7-10,11-15$ and $>16$ cells/cluster), the number of cluster groups in each outlet were counted and their $100 \%$ stacked column charts were statistically analyzed. The results, as presented in Fig. 3C, revealed that all clusters were mainly distributed in the III, IV and $\mathrm{V}$ channels, and larger clusters (cells/cluster $>10$ ) only emerged in channels IV and $\mathrm{V}$. Therefore, in order to analyze the characteristics of large clusters, the corresponding outlet (either IV or V) requires selection. Images of the AO fluorescence staining under the fluorescein isothiocyanate light are shown in Fig. 4A-E, which presents the results of Fig. 3C visually.

Viability of the chip. Subsequent to analyzing the recovery characteristics of each channel, the present study aimed to examine whether the chip exerted any influence on the viability of cells, therefore, a cell viability assay was performed using trypan blue.

Through analysis of the cluster samples collected from the outlets (III-V), the results (Fig. 3D) revealed that, following 10 min of sorting by the chip, the cell viability in the clusters did not differ significantly compared with that in the control group. This indicates that the clusters collected by the chip may be used for further downstream analysis.

Establishment of a diagnosis model. Tumor cells and mesothelial cells are always difficult to differentiate clinically, particularly those stimulated to proliferate under inflammation. AO fluorescence dye can be used to stain the nucleotide chain different colors. It combines with double-stranded DNA by embedding between the two chains and emits a bright green fluorescence. In the case of single-stranded DNA and RNA, the dye is deposited on its phosphate group by electrostatic attraction, which results in the emission of orange-red fluorescence (24). Therefore, the present study aimed to assess whether AO staining can be used, by analyzing each image color channel characteristic (green or red), to evaluate the 
A

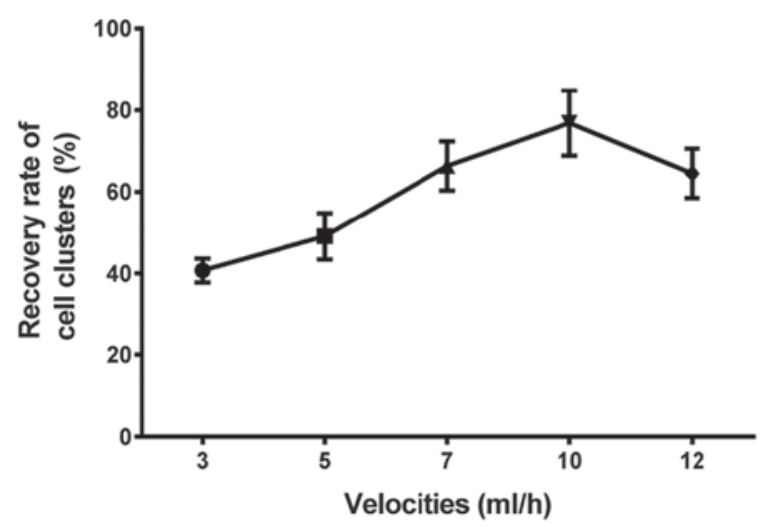

C

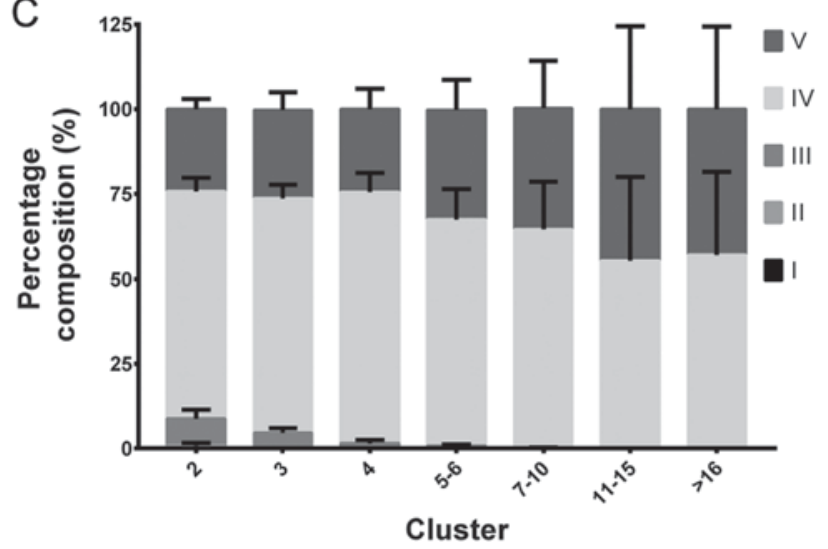

B

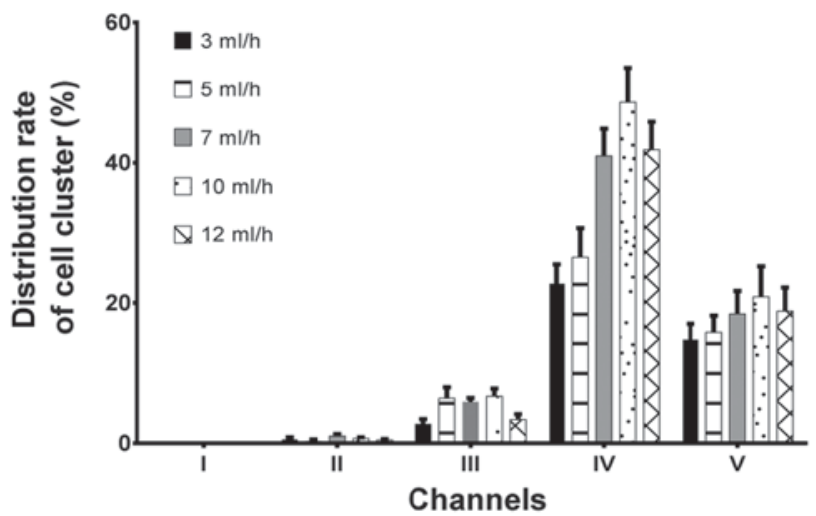

D

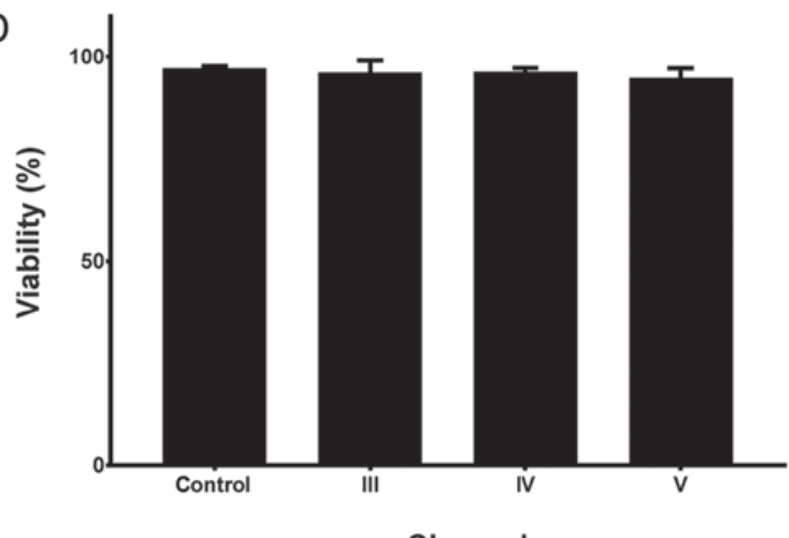

Figure 3. Recovery, distribution and viability characteristics of the sorting chip. (A) Recovery rate of the cell clusters under different velocities. (B) Distribution rate of the cell clusters under different velocities in each channel group. (C) Percentage composition of the cell cluster groups (Va=10 $\mathrm{ml} / \mathrm{h}$ and $\mathrm{Vb}=8.5 \mathrm{ml} / \mathrm{h}$ ) in each channel group. (D) Viability of the clusters harvested from each outlet. Error bars represent the mean \pm standard error of the mean of at least three independent experiments.
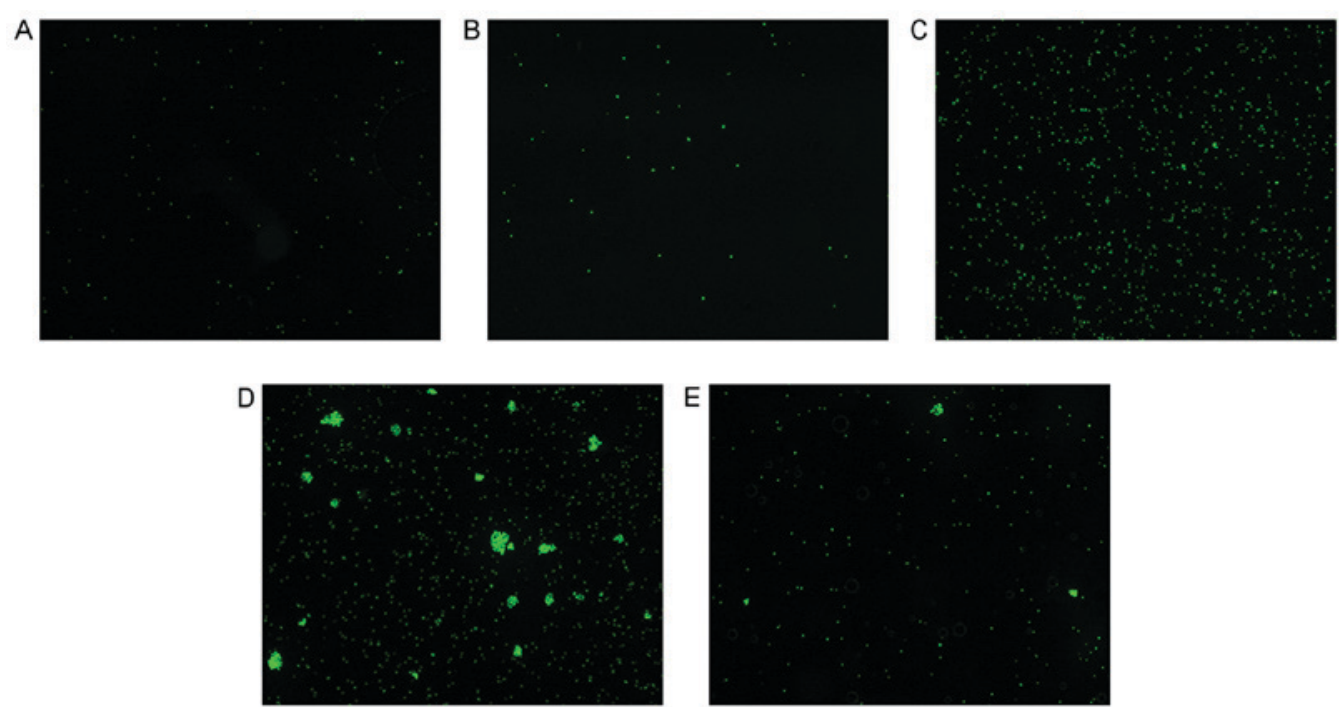

Figure 4. Cells and clusters collected from outlets I-V. (A) Outlet I. (B) Outlet II. (C) Outlet III. (D) Outlet IV. (E) Outlet V. All the images were captured at magnification, $\mathrm{x} 4$.

proliferation characteristics of tumor cells and mesothelium cells to distinguish between them.

In the present study, the A549 lung cancer cell line and SV40 virus immortalized Met-5A human pleural mesothelial cell line were used to conduct a comparative experiment. The WBCs extracted from the whole blood of a healthy donor were used as the control group. Samples were collected from each outlet (three samples for each cell line) and stained with $\mathrm{AO}$ subsequent to mixing with $0.01 \mathrm{M}$ PBS to a final concentration of $1 \times 10^{8}$ cells $/ \mathrm{ml}$ (with each cluster counted as one cell). The fluorescent results are 
A549
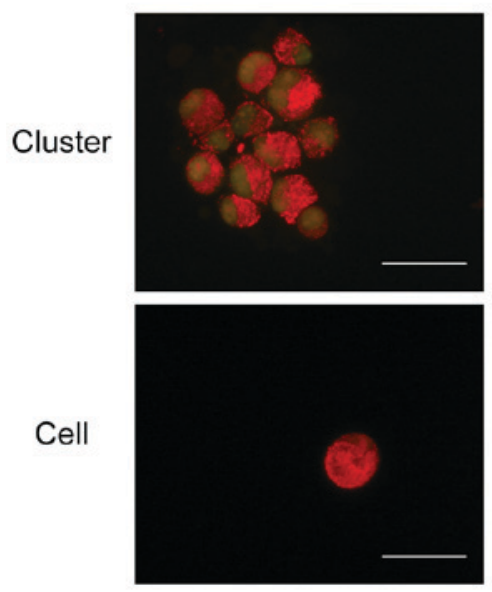

Met-5A
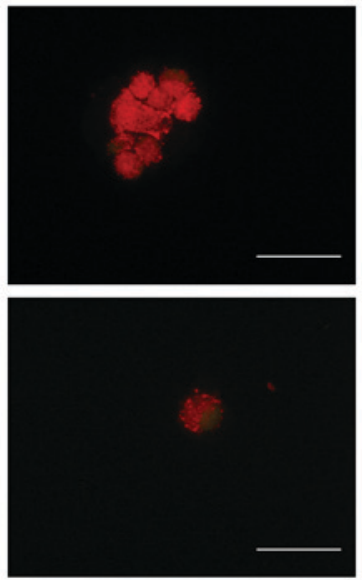

WBC
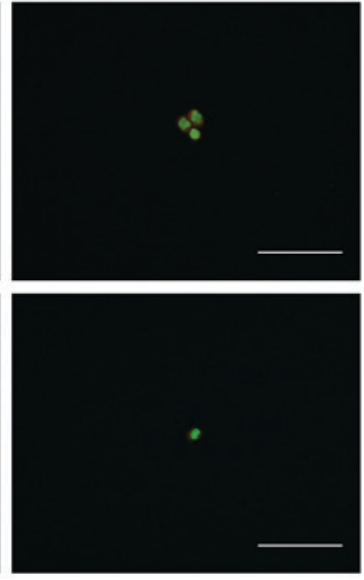

Figure 5. Fluorescence images. Images of examples of each cell and cluster model. Scale bar=50 $\mu \mathrm{m}$. WBC, white blood cell.

presented in Fig. 5, which reveal that the mesothelial cell clusters and lung cancer cell clusters exhibited a large area of orange fluorescence, and it was not possible to distinguish the nucleus boundary for the majority of them. By contrast, the WBCs had a clear nuclear outline and exhibited a higher level of green fluorescence compared with the mesothelial or lung cancer cells. For individual cells, the outlines of the nucleus in the mesothelial and lung cancer cells were clearer compared with those in the WBCs, which may indicate that this phenomenon is associated with cell adhesion and proliferation ability. However, further experiments are required to confirm this.

Therefore, an analysis system was established using Matlab to examine various cells and cell clusters to determine whether there are features that may be used to distinguish different types of cells or clusters. A total number of 375 images were analyzed, including 70 of A549 clusters and 50 of single cells; 80 of Met-5A clusters and 39 of single cells; and 36 of WBC clusters and 100 of single cells. The selected features for image analysis were commonly used indicators, including the following: i) mean energy value, ii) energy variance, iii) mean entropy value, iv) entropy variance, v) mean contrast value, vi) contrast variance, vii) mean correlation value, viii) correlation variance and ix) color histogram.

The co-occurrence matrix eigenvalue results are presented in Fig. 6. For clusters in channel R (Fig. 6A), seven statistically significant differences were found between the A549 and Met-5A cell lines. For clusters in channel G (Fig. 6B), seven statistically significant differences were also identified between the Met-5A and A549 cells. However, there were marginal differences between each feature. For single cells (Fig. 7), statistically significant differences were identified in four features in channel G (Fig. 7A) and six features in channel R (Fig. 7B) between the cell types. For clusters in channel R/G (Fig. 8A), statistically significant differences were identified between the Met-5A and A549 cells for only two features. For single cells in channel R/G (Fig. 8B), five features differed significantly between the Met-5A and A549 cells.

These results suggest that it is feasible to distinguish between A549 and Met-5A cells using AO fluorescence staining in the $\mathrm{R}$ or $\mathrm{G}$ channels, and that there are a greater number of features distinguishing tumor clusters from normal clusters compared with single tumor cells.

Therefore, it is possible to distinguish between different types of cells by screening a greater number of features, and by setting threshold and confidence intervals and assessing the accuracy of each feature, the identification of tumor cells may be improved in the future.

Identification of pleural effusion in patients. Subsequent to the collection of pleural effusion samples from two patients who had been diagnosed with lung cancer at Tianjin Chest Hospital, chip sorting and image analysis were performed. A representative example is shown in Fig. 9, which presents the experimental results of one patient. From the H\&E staining, tumor clusters were identified. The immunohistochemical staining results were as follows: CEA $(+)$, mesothelial cell $(-)$, tumor protein P53 (+) and TTF-1 (+), suggesting that the clusters are the adenocarcinoma type. For each cluster type, three images were selected. The characteristic identification analysis revealed that six features were significantly different in channel $\mathrm{R}$, and five features were significantly different in channel G. This indicated that, for clinical specimens, different types of clusters can be differentiated by the platform.

\section{Discussion}

As malignant pleural effusion mainly consists of the following components: Red blood cells, WBCs, mesothelial cells and tumor cells or tumor clusters, it is possible to identify single cells by analyzing various characteristics, including size $(26,27)$, electric features (28), acoustic features $(29,30)$ and immunomagnetic features $(31,32)$. However, the gold standard of tumor diagnosis remains its pathological appearance. Additionally, with the exception of circulating tumor clusters $(33,34)$, there remains a lack of systematic analysis of pleural effusion clusters. Therefore, the present study established a microfluidic chip and algorithm based on cell sorting and a morphological method for pleural effusion cluster identification.

In the present study, microfluidic technology was used to separate tumor cells and clusters from pleural effusion samples 
A a

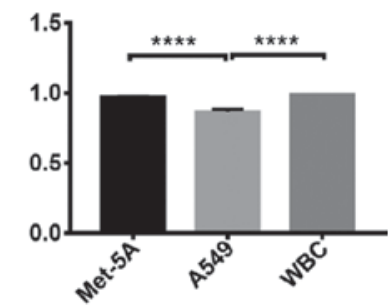

d cluster-Ent-SD-G

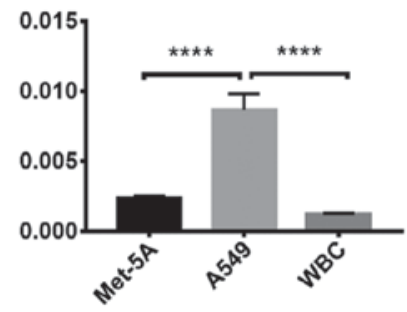

g cluster-Cor-M-G

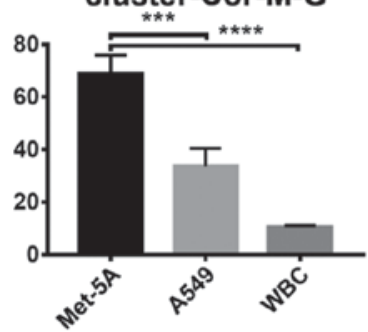

B a cluster-Ene-M-R

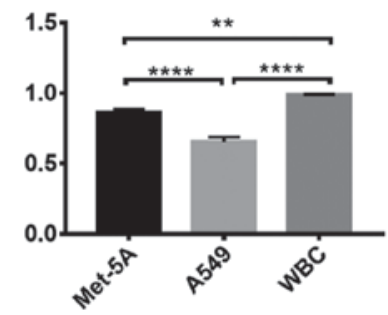

d cluster-Ent-SD-R

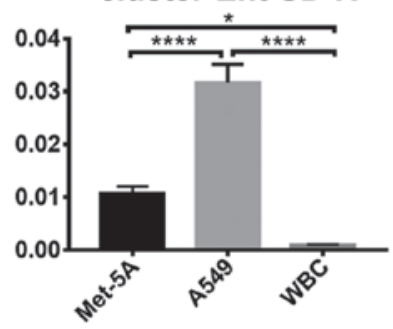

g cluster-Cor-M-R

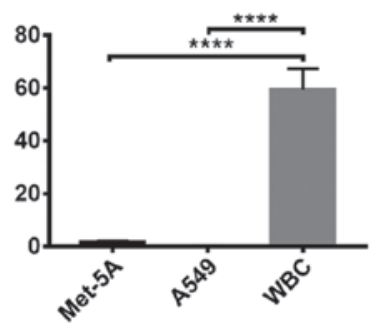

b cluster-Ene-SD-G

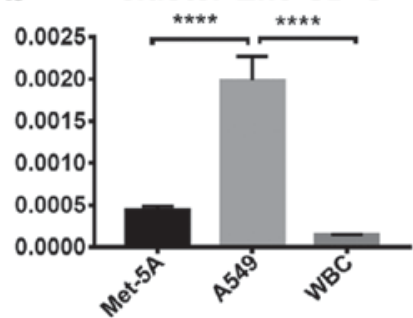

e

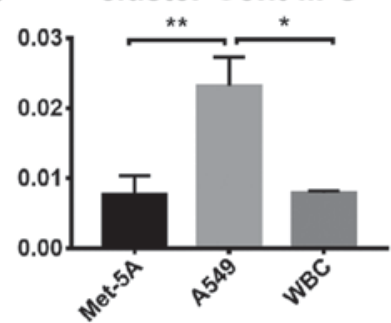

h

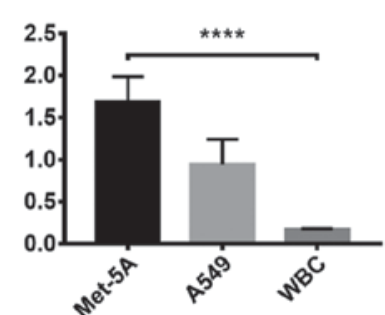

b

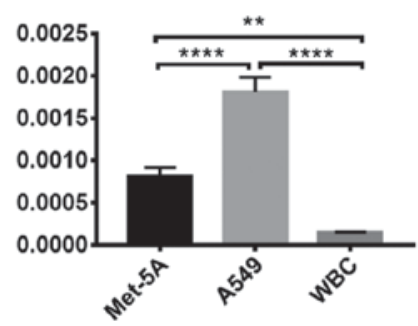

e

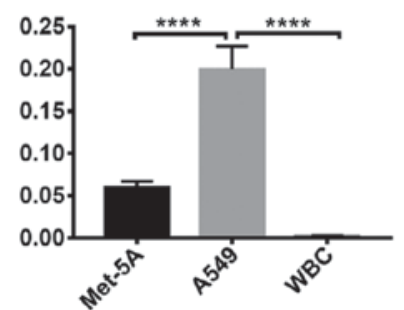

h

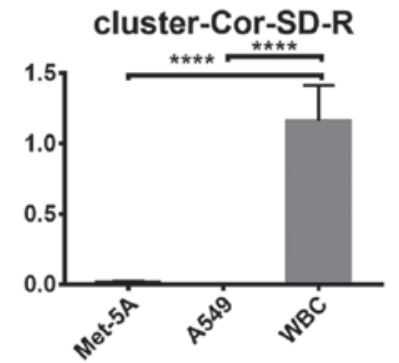

c cluster-Ent-M-G

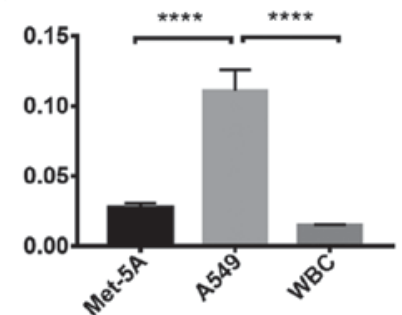

f cluster-Cont-SD-G

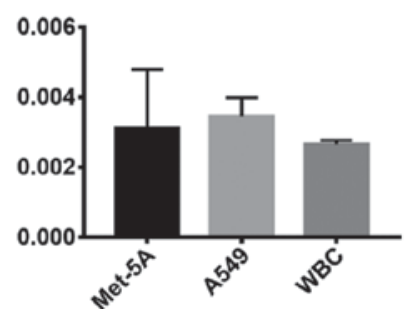

i

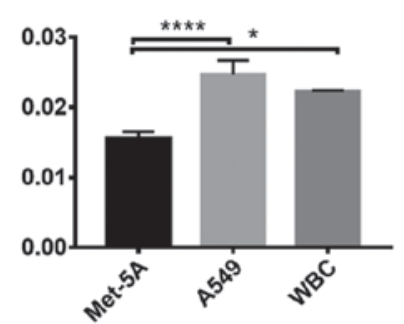

C

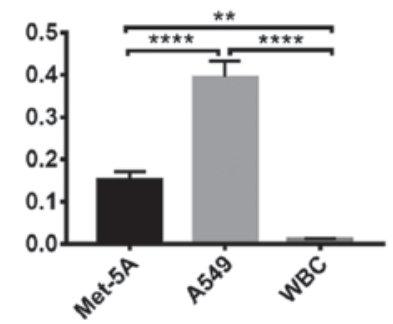

f

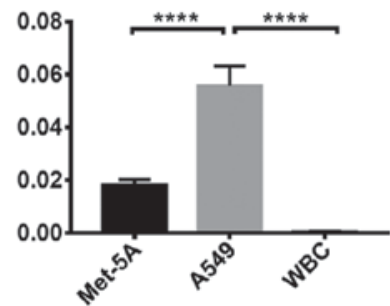

i

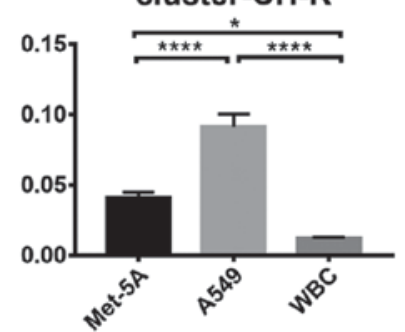

Figure 6. Comparison of the features between each cluster. (A) G values of each cluster feature: (Aa) Mean energy value, (Ab) energy variance, (Ac) mean entropy value, (Ad) entropy variance, $(\mathrm{Ae})$ mean contrast value, (Af) contrast variance, (Ag) mean correlation value, (Ah) correlation variance and (Ai) color histogram. (B) $\mathrm{R}$ values of each feature: (Ba) Mean energy value, (Bb) energy variance, (Bc) mean entropy value, (Bd) entropy variance, (Be) mean contrast value, $(\mathrm{Bf})$ contrast variance, $(\mathrm{Bg})$ mean correlation value, $(\mathrm{Bh})$ correlation variance and $(\mathrm{Bi})$ color histogram. The vertical axis represents the feature values in channel $\mathrm{G}$ or R. The horizontal axis represents the three cell types used. One-way analysis of variance was used for the analysis of each group. Error bars represent the mean \pm standard error of the mean. ${ }^{*} \mathrm{P}<0.05,{ }^{* * *} \mathrm{P}<0.01,{ }^{* * * *} \mathrm{P}<0.001$ and ${ }^{* * * *} \mathrm{P}<0.0001$. WBC, white blood cell. 
A a

\section{Cell-Ene-M-G}

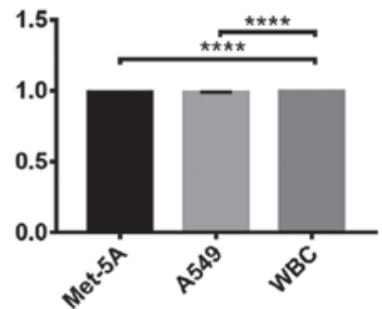

d

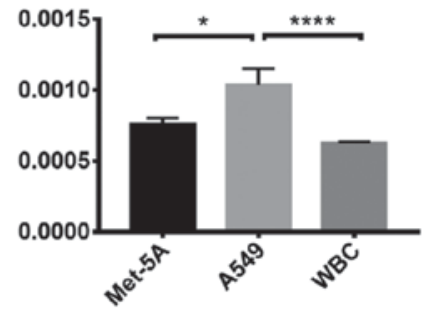

g

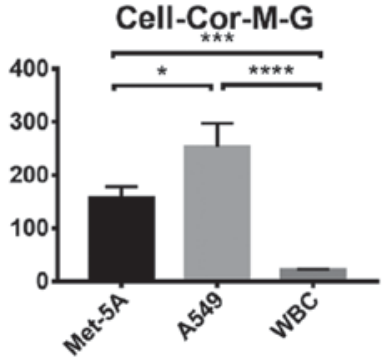

B a

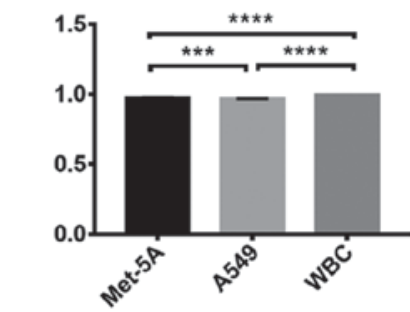

d

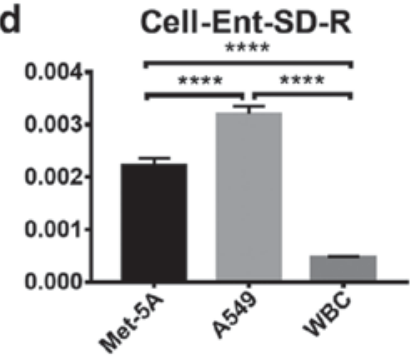

g

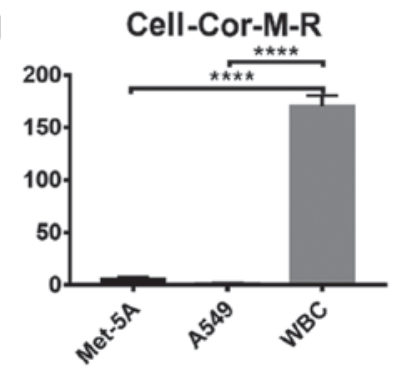

b

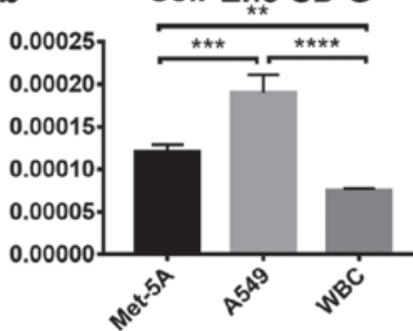

e

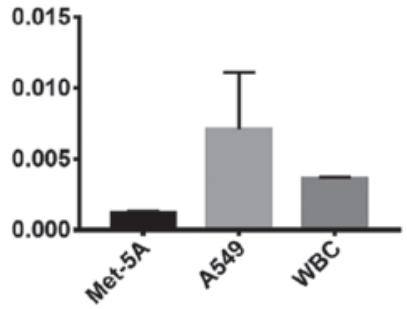

h

Cell-Cor-SD-G

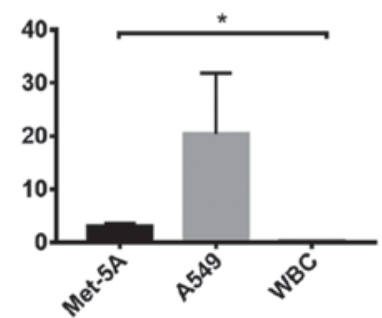

b

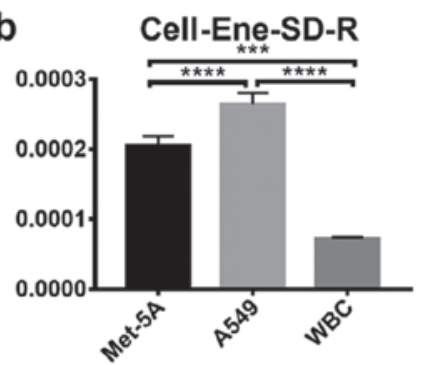

e

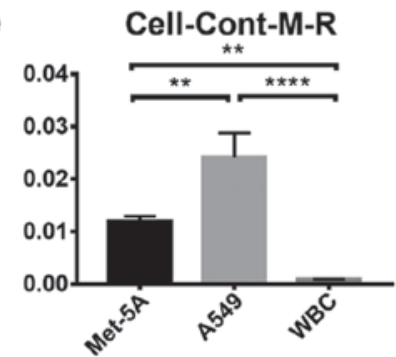

h
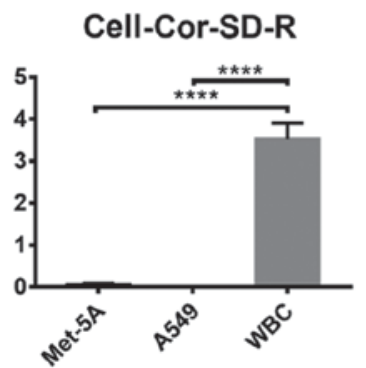

C

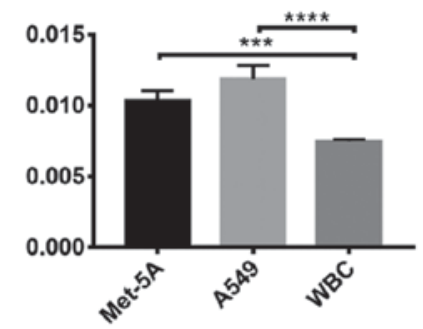

f

Cell-Cont-SD-G

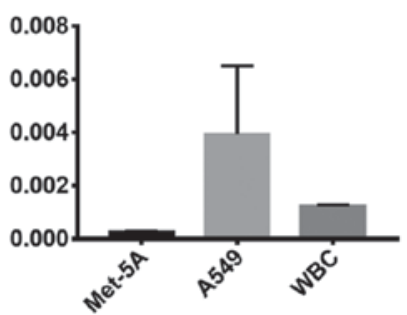

i

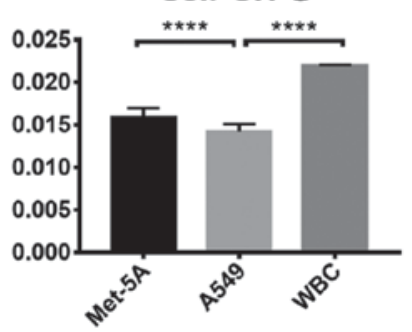

C

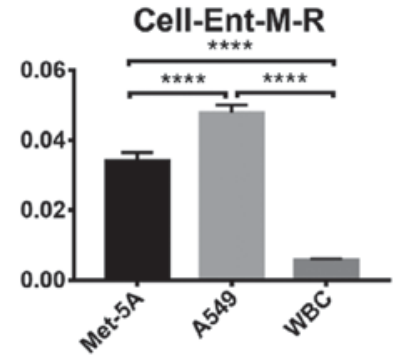

f

Cell-Cont-SD-R

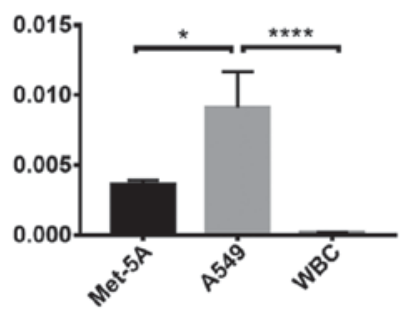

i

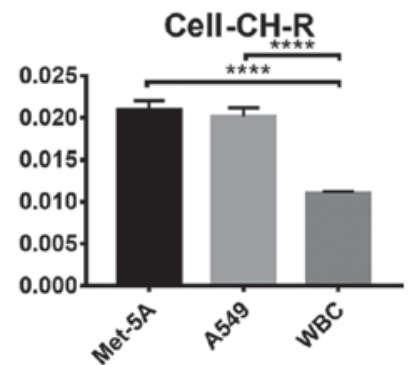

Figure 7. Comparison of the features between cells. (A) G values of each cell feature: (Aa) Mean energy value, (Ab) energy variance, (Ac) mean entropy value, (Ad) entropy variance, (Ae) mean contrast value, (Af) contrast variance, (Ag) mean correlation value, (Ah) correlation variance and (Ai) color histogram. (B) $\mathrm{R}$ values of each cell feature: $(\mathrm{Ba})$ Mean energy value, $(\mathrm{Bb})$ energy variance, $(\mathrm{Bc})$ mean entropy value, (Bd) entropy variance, (Be) mean contrast value, (Bf) contrast variance, $(\mathrm{Bg})$ mean correlation value, $(\mathrm{Bh})$ correlation variance and (Bi) color histogram. The vertical axis represents the feature values in channel $\mathrm{G}$ or R. The horizontal axis represents the three cell types used. One-way analysis of variance was used for the analysis. of each group. Error bars represent the mean \pm standard error of the mean. ${ }^{*} \mathrm{P}<0.05,{ }^{* *} \mathrm{P}<0.01,{ }^{* * * *} \mathrm{P}<0.001$ and ${ }^{* * * * *} \mathrm{P}<0.0001$. WBC, white blood cell. 


\section{A a Cluster-Ene-M-R/G}

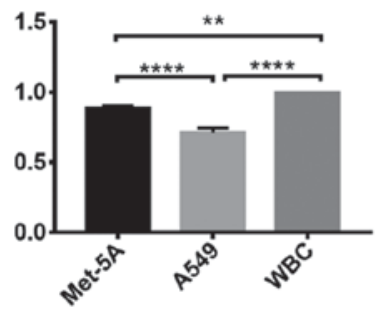

d Cluster-Ent-SD-R/G

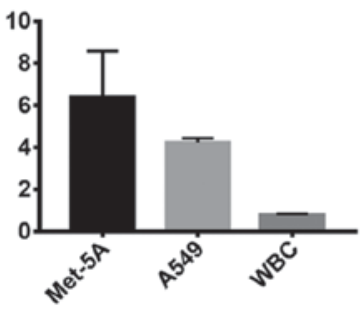

g Cluster-Cor-M-R/G

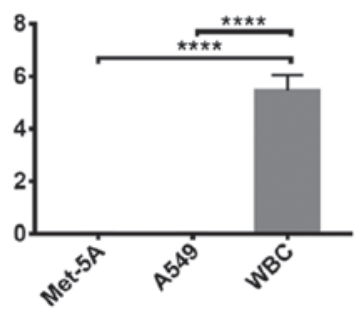

B a Cell-Ene-M-R/G

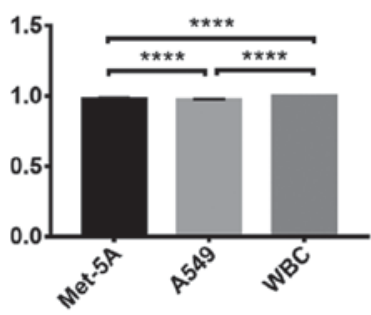

d Cell-Ent-SD-R/G

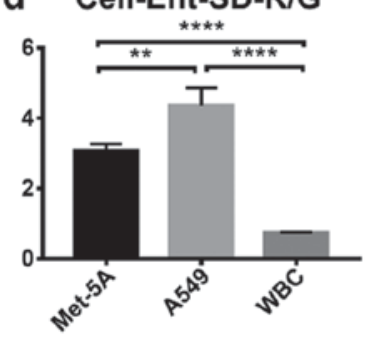

g Cell-Cor-M-R/G

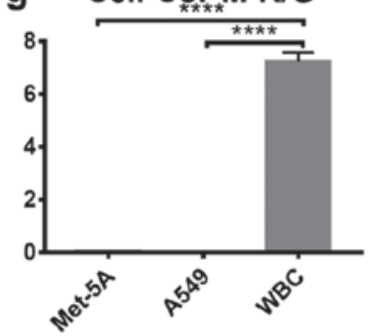

b Cluster-Ene-SD-R/G

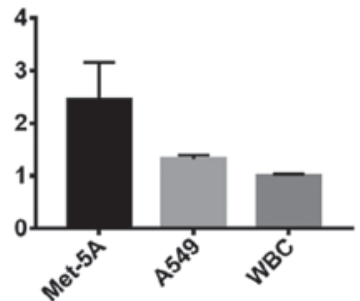

e Cluster-Cont-M-R/G

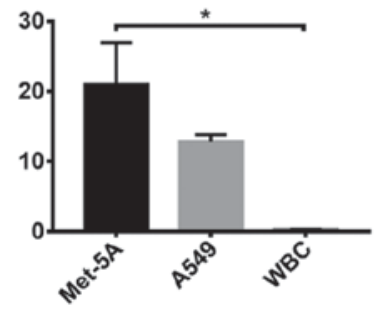

h Cluster-Cor-SD-R/G

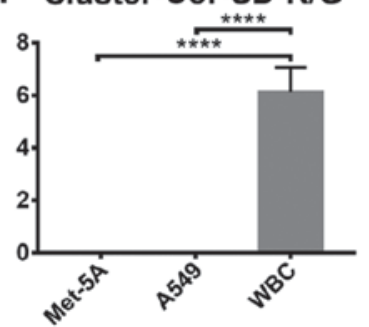

b Cell-Ene-SD-R/G

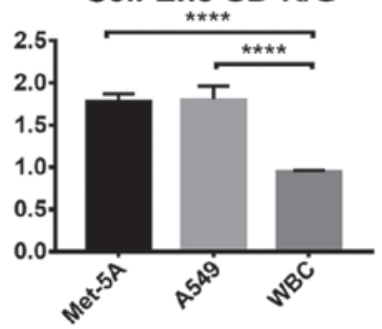

e

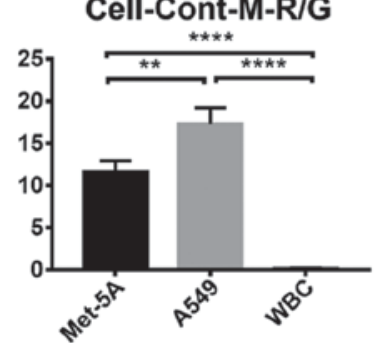

h

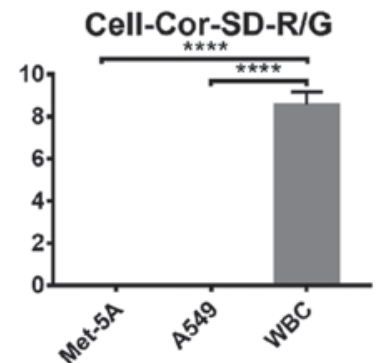

C Cluster-Ent-M-R/G

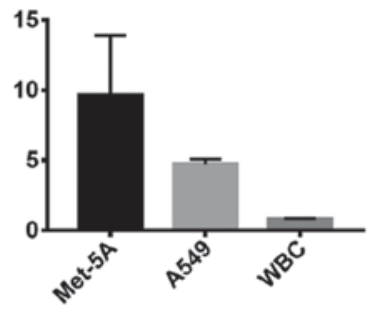

f Cluster-Cont-SD-R/G

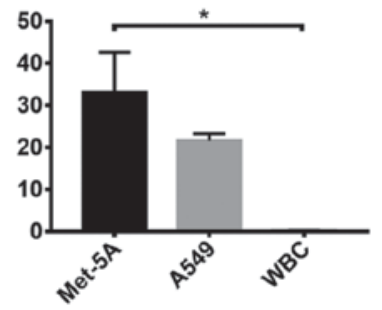

i Cluster-CH-R/G

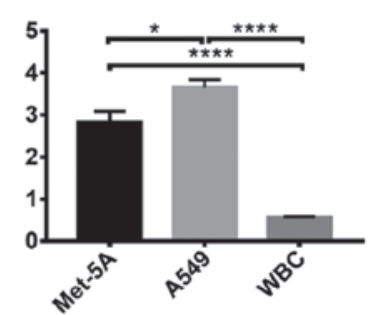

C

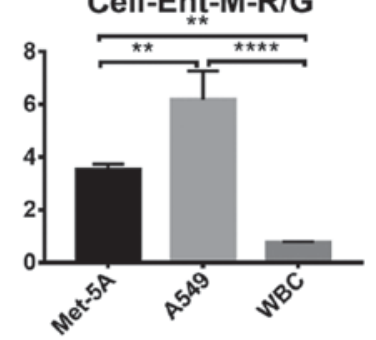

f

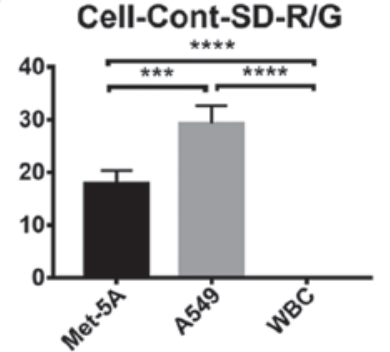

i

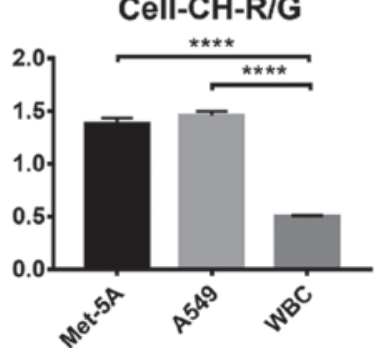

Figure $8 . \mathrm{R} / \mathrm{G}$ values of clusters and cells. R/G values of each (A) cell cluster for (Aa) mean energy value, (Ab) energy variance, (Ac) mean entropy value, (Ad) entropy variance, (Ae) mean contrast value, (Af) contrast variance, (Ag) mean correlation value, (Ah) correlation variance and (Ai) color histogram. (B) $\mathrm{R} / \mathrm{G}$ values of each single cell for $(\mathrm{Ba})$ mean energy value, $(\mathrm{Bb})$ energy variance, ( $\mathrm{Bc}$ ) mean entropy value, (Bd) entropy variance, (Be) mean contrast value, $(\mathrm{Bf})$ contrast variance, $(\mathrm{Bg})$ mean correlation value, $(\mathrm{Bh})$ correlation variance and $(\mathrm{Bi})$ color histogram. The vertical axis represents the feature values in channel R/G. The horizontal axis represents the three cell types used. One-way analysis of variance was used for the analysis of each group. Error bars represent the mean \pm standard error of the mean. ${ }^{*} \mathrm{P}<0.05,{ }^{* * *} \mathrm{P}<0.01,{ }^{* * * *} \mathrm{P}<0.001$ and ${ }^{* * * *} \mathrm{P}<0.0001$. WBC, white blood cell. 
A

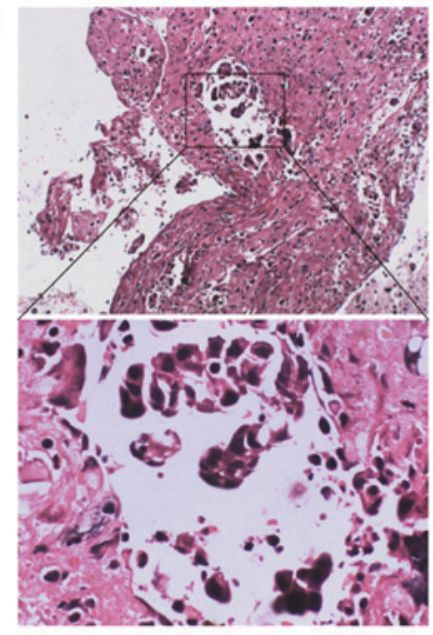

B

Lung adenocarcinoma cluster

WBC cluster

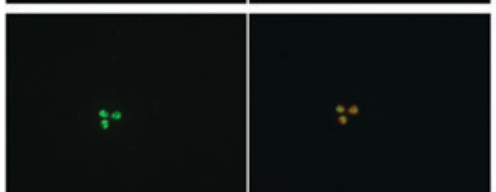

\section{b}

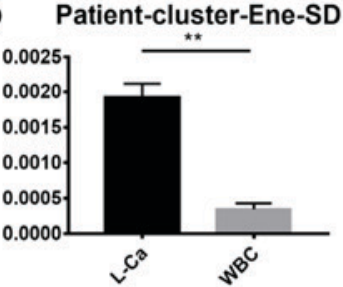

e

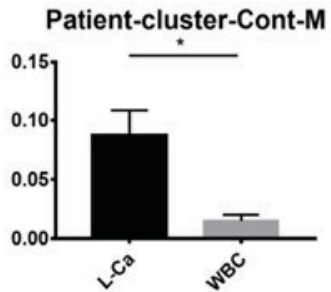

h

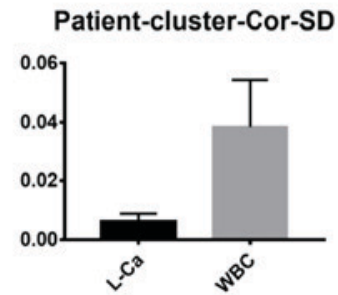

C

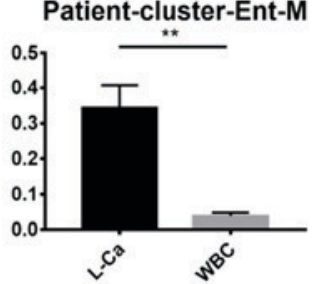

d Patient-cluster-Ent-SD

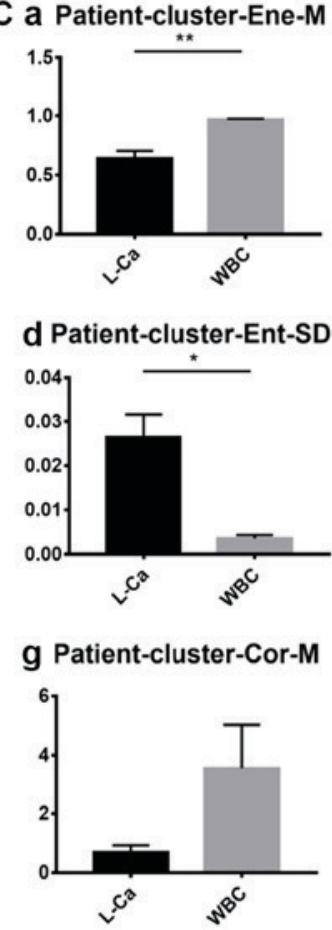

g Patient-cluster-Cor-M

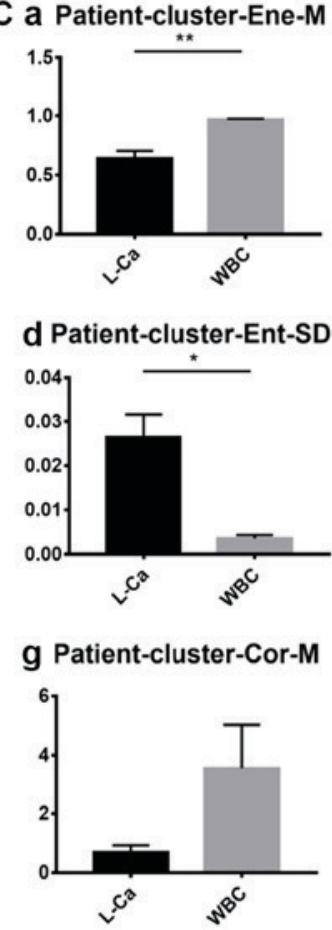

Figure 9. Pleural effusion sample analysis from patients with lung cancer. (A) Lung tissue biopsy hematoxylin and eosin staining results. Upper panel, magnification, x10 and lower panel, magnification, x40. (B) Clusters stained by acridine orange in pleural effusion samples under FITC and UV light. Magnification, $\mathrm{x}$ 40. (C) $\mathrm{R}$ values of each cluster feature: $(\mathrm{Ca})$ Mean energy value, $(\mathrm{Cb})$ energy variance, $(\mathrm{Cc})$ mean entropy value, $(\mathrm{Cd})$ entropy variance, $(\mathrm{Ce})$ mean contrast value, $(\mathrm{Cf})$ contrast variance, $(\mathrm{Cg})$ mean correlation value, $(\mathrm{Ch})$ correlation variance and $(\mathrm{Ci})$ color histogram The vertical axis represents the feature values of channel R. The horizontal axis includes the patient clusters assessed. Unpaired t-test analysis was used for each group. Error bars represent the mean \pm standard error of the mean. "P<0.05 and ${ }^{* *} \mathrm{P}<0.01$. FITC, fluorescein isothiocyanate; UV, ultraviolet; WBC, white blood cell; L-Ca, lung cancer.

obtained from patients and identify them from the selective outlets. For isolation, the most suitable velocity pair for sorting was identified as $\mathrm{Va}=0 \mathrm{ml} / \mathrm{h}$ and $\mathrm{Vb}=8.5 \mathrm{ml} / \mathrm{h}$, and with clusters being harvested from outlets IV and V and single cells gathered mainly from outlet III, the total recovery rate of the clusters was $\sim 80 \%$. In the present study, almost $20 \%$ of the target clusters were lost. This absence frequency may be due to the long duration of the running process, which results in the phenomenon of the sample in the horizontally-oriented inlet pipeline $(\sim 10 \mathrm{~cm})$, which can be avoided by using a vertical setting on the syringe pumps.

For identification, AO staining was used in order to make use of its non-specificity. Usually, specific cell markers can be lost due to the heterogeneity of biomarkers, particularly in pleural effusion. However, the internal nucleic acid distribution is maintained. Therefore, by staining the cells with AO under UV light, the distribution of nucleic acids can be detected using this method to visualize and analyze the composition of the nucleus. In addition, the color difference between double chain and single nucleic acid can be used to determine the cell proliferation condition. Using a set of image analyzers, the tumor cells or clusters were characterized and distinguished from the non-tumor cells or clusters. The characteristics of different color channel ratios may be preliminarily distinguishable between different cell clusters and single cells. However, as the present study used only one lung cancer cell line, it was not possible to separate the identifying columns into sub-types. For future investigations, the addition of additional lung cancer-associated cell lines may be used to fulfill the model. In addition, the pleural effusion contains numerous tissue fragments, even fibrinous aggregates; however, the image recognition principle in the present study was based on the shape, texture, color, contrast or other features of the captured images. Tissue fragments or fibrin are different from cells, and certain fragments do not have cellular structures. At present, the procedure in the present study does not collect data to account for this, however, through subsequent improvements, these data can be collected for characteristic recognition, or by setting thresholds of cells to rule out the foreign body. 
In conclusion, on the basis of cell size, a suitable microfluidic chip was designed for hydrothorax tumor cell clusters: When a cell cluster has $>10$ cells, they appear only in channel IV and V of the chip. AO fluorescent staining of the cells was used, and this revealed certain identification features used to distinguish between tumor and non-tumor cell clusters. The characteristics of the two selected cell lines indicate, to a certain extent, that this method may be used to identify lung cancer cells and mesothelial cells in malignant pleural effusion.

\section{Acknowledgements}

The authors would like to thank Dr Zhao Gang (Department of Pathology, Cancer Hospital, Tianjin Medical University, Tianjin, China) for assisting with pathological technology and diagnosis.

\section{Funding}

The present study was supported by the National Natural Science Foundation of China through the Operational Competitiveness Program and national funding from the Natural Science Foundation of Tianjin City (grant nos. 30973157, 81772945 and 15JCYBJC268000).

\section{Availability of data and materials}

The datasets used and/or analyzed in the present study are available from the corresponding author on reasonable request.

\section{Authors' contributions}

LZ designed the research, collected the sample, performed the experiment, analyzed the data and wrote the manuscript. YY assisted with the chip experiment. MZ and ZZ designed the feature algorithm and analyzed images of samples. YG and XW contributed to patient sample collection. FZ and XS contributed significantly to statistical analysis. All authors read and approved the final manuscript.

\section{Ethics approval and consent to participate}

The study was approved by the Ethics Committee of Tianjin Medical University (Tianjin, China; study no. TMUhMEC2017012), and the patients or their families signed informed consent.

\section{Patient consent for publication}

Not applicable.

\section{Competing interests}

The authors declare that they have no competing interests.

\section{References}

1. Torre LA, Bray F, Siegel RL, Ferlay J, Lortet-Tieulent J and Jemal A: Global cancer statistics, 2012. CA Cancer J Clin 65 $87-108,2015$
2. Toufektzian L, Sepsas E, Drossos V, Gkiozos I and Syrigos K: Pleural lavage cytology: Where do we stand? Lung Cancer 83: 14-22, 2014.

3. Tsuchido K, Yamada M, Satou T, Otsuki Y, Shimizu S and Kobayashi H: Cytology of sclerosing epithelioid fibrosarcoma in pleural effusion. Diagn Cytopathol 38: 748-753, 2010.

4. Huang CC and Michael CW: Cytomorphological features of metastatic squamous cell carcinoma in serous effusions. Cytopathology 25: 112-119, 2014.

5. Omori M, Kondo T, Yuminamochi T, Nakazawa K, Ishii Y, Fukasawa H, Hashi A and Hirata S: Cytologic features of ovarian granulosa cell tumors in pleural and ascitic fluids. Diagn Cytopathol 43: 581-584, 2015.

6. Kosmas K, Tsonou A, Mitropoulou G, Salemi E, Kazi D and Theofanopoulou A: Malignant pleural effusion from papillary thyroid carcinoma diagnosed by pleural effusion cytology: A case report. Diagn Cytopathol 46: 204-207, 2018.

7. Ferreiro L, Toubes ME and Valdes L: Contribution of pleural fluid analysis to the diagnosis of pleural effusion. Med Clin (Barc) 145: 171-177, 2015.

8. Che J, Mach AJ, Go DE, Talati I, Ying Y, Rao J, Kulkarni RP and Di Carlo D: Microfluidic purification and concentration of malignant pleural effusions for improved molecular and cytomorphological diagnostics. PLoS One 8: e78194, 2013.

9. Rashmi K, Shashikala P, Hiremath S and Basavaraj HG: Cells in pleural fluid and their value in differential diagnosis. J Cytology 25: 138-143, 2008.

10. Attanoos RL, Galateau-Salle F, Gibbs AR, Muller S, Ghandour F and Dojcinov SD: Primary thymic epithelial tumours of the pleura mimicking malignant mesothelioma. Histopathology 41: 42-49, 2002.

11. Wendel M, Bazhenova L, Boshuizen R, Kolatkar A, Honnatti M, Cho EH, Marrinucci D, Sandhu A, Perricone A, Thistlethwaite P, et al: Fluid biopsy for circulating tumor cell identification in patients with early-and late-stage non-small cell lung cancer: A glimpse into lung cancer biology. Phys Biol Feb; 9: 016005, 2012. doi: 10.1088/1478-3967/9/1/016005

12. Hsieh TC, Huang WW, Lai CL, Tsao SM and Su CC: Diagnostic value of tumor markers in lung adenocarcinoma-associated cytologically negative pleural effusions. Cancer Cytopathol 121: 883-888, 2013.

13. Bisht B, Handa U, Mohan H and Lehl SS: Complementary value of DNA flow cytometry and image morphometry in detection of malignant cells in effusion fluids. Malays J Pathol 36: 83-90, 2014.

14. Ai T, Tabe Y, Takemura H, Kimura K, Takahashi T, Yang H, Tsuchiya K, Konishi A, Uchihashi K, Horii T and Ohsaka A: Novel flowcytometry-based approach of malignant cell detection in body fluids using an automated hematology analyzer. PLoS One 13: e0190886, 2018.

15. Miédougé M, Rouzaud P, Salama G, Pujazon MC, Vincent C, Mauduyt MA, Reyre J, Carles P and Serre G: Evaluation of seven tumour markers in pleural fluid for the diagnosis of malignant effusions. Br J Cancer 81: 1059-1065, 1999.

16. Yanaihara N, Caplen N Bowman E, Seike M, Kumamoto K, Yi M, Stephens RM, Okamoto A, Yokota J, Tanaka T, et al: Unique microRNA molecular profiles in lung cancer diagnosis and prognosis. Cancer Cell 9: 189-198, 2006.

17. Hooper C, Lee YC, Maskell N and BTS Pleural Guideline Group: Investigation of a unilateral pleural effusion in adults: British thoracic society pleural disease guideline 2010. Thorax 65: ii4-ii17, 2010.

18. Swiderek J, Morcos S, Donthireddy V, Surapaneni R, Jackson-Thompson V, Schultz L, Kini S and Kvale P: Prospective study to determine the volume of pleural fluid required to diagnose malignancy. Chest 137: 68-73, 2010.

19. Rooper LM, Ali SZ and Olson MT: A minimum fluid volume of $75 \mathrm{ml}$ is needed to ensure adequacy in a pleural effusion: A retrospective analysis of 2540 Cases. Cancer Cytopathol 122: 657-665, 2014

20. Scholtens TM, Schreuder F, Ligthart ST, Swennenhuis JF, Tibbe AGJ, Greve J and Terstappen LW: Cell Tracks TDI: An image cytometer for cell characterization. Cytometry A 79: 203-213, 2011.

21. Yasuda K, Hattori A, Kim H, Terazono H, Hayashi M, Takei H, Kaneko T and Nomura F: Non-destructive on-chip imaging flow cell-sorting system for on-chip cellomics. Microfluidics and Nanofluidics 14: 907-931, 2013.

22. Smith ZJ, Gao T, Chu K, Lane SM, Matthews DL, Dwyre DM, Hood J, Tatsukawa K, Heifetz L and Wachsmann-Hogiu S: Single-step preparation and image-based counting of minute volumes of human blood. Lab Chip 14: 3029-3036, 2014. 
23. Zhao M, Wu A, Song J, Sun X and Dong N: Automatic screening of cervical cells using block image processing. Biomed Eng Online 15: 14, 2016.

24. Amado AM, Pazin WM, Ito AS, Kuzmin VA and Borissevitch IE: Acridine orange interaction with DNA: Effect of ionic strength Biochim Biophys Acta Gen Subj 1861: 900-909, 2017.

25. Liu M, Li R, Tang Y, Chang J, Han R, Zhang S, Jiang N and Ma F: New applications of the acridine orange fluorescence staining method: Screening for circulating tumor cells. Oncol Lett 13: 2221-2229, 2017.

26. Vona G Sabile A, Louha M, Sitruk V, Romana S, Schütze K, Capron F, Franco D, Pazzagli M, Vekemans M, et al: Isolation by size of epithelial tumor cells-A new method for the immunomorphological and molecular characterization of circulating tumor cells. Am J Pathol 156: 57-63, 2000.

27. Mohamed H, Murray M, Turner JN and Caggana M: Isolation of tumor cells using size and deformation. J Chromatogr A 1216: 8289-8295, 2009.

28. Yang H, Li L, Ding Y Ye D, Wang Y, Cui S and Liao L: Molecularly imprinted electrochemical sensor based on bioinspired Au microflowers for ultra-trace cholesterol assay. Biosens Bioelectron 92: 748-754, 2017.

29. Fakhfouri A, Devendran C, Collins J, Ai Y and Neild A: Virtual membrane for filtration of particles using surface acoustic waves (SAW). Lab Chip 16: 3515-3523, 2016.
30. Ren L, Chen Y, Li P, Mao Z, Huang PH, Rufo J, Guo F, Wang L, McCoy JP, Levine SJ and Huang TJ: A high-throughput acoustic cell sorter. Lab Chip 15: 3870-3879, 2015.

31. Adams JD, Kim U and Soh HT: Multitarget magnetic activated cell sorter. Proc Natl Acad Sci USA 105: 18165-18170, 2008.

32. Osman O, Toru S, Dumas-Bouchiat F, Dempsey NM, Haddour N, Zanini LF, Buret F, Reyne G and Frenea-Robin M: Microfluidic immunomagnetic cell separation using integrated permanent micromagnets. Biomicrofluidics 7: 54115, 2013.

33. Sarioglu AF, Aceto N, Kojic N, Donaldson MC, Zeinali M, Hamza B, Engstrom A, Zhu H, Sundaresan TK, Miyamoto DT, et al: A microfluidic device for label-free, physical capture of circulating tumor cell clusters. Nat Methods 12: 685-691, 2015

34. Au SH, Edd J, Stoddard AE, Wong KHK, Fachin F, Maheswaran S, Haber DA, Stott SL, Kapur R and Toner M: Microfluidic isolation of circulating tumor cell clusters by size and asymmetry. Sci Rep 7: 2433, 2017.

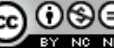

This work is licensed under a Creative Commons Attribution-NonCommercial-NoDerivatives 4.0 International (CC BY-NC-ND 4.0) License. 